\title{
ANATOMIA DO LENHO DE ESCULTURAS DO MUSEU VICENTE PALLOTTI (SANTA MARIA, RS, BRASIL). 1 - DESCRIÇÃO E IDENTIFICAÇÃO ANATÔMICA DO "MENINO"
}

\author{
PAULO FERNANDO DOS SANTOS MACHADO² JOSÉ NEWTON CARDOSO MARCHIORI ${ }^{3}$ \\ DANIELI SANCHEZ ${ }^{4}$
}

\section{RESUMO}

O lenho do "Menino", escultura integrante do acervo do Museu Vicente Pallotti (Santa Maria, RS, Brasil), foi identificado ao microscópio como pertencente ao gênero Tilia L. (Malvaceae, ex Tiliaceae), provando que a obra é de origem européia, não sul-americana.

Palavras-chave: Anatomia da Madeira; Menino; Museu Vicente Pallotti; Tilia.

\section{ABSTRACT}

[Wood anatomy of sculptures from Vicente Pallotti Museum (Santa Maria, Rio Grande do Sul State, Brazil). 1 - Description and anatomical identification of the sculpture named "Boy"].

The wood of the sculpture named "Boy", that integrates the collection of Museum Vicente Pallotti (Santa Maria, Rio Grande do Sul State, Brazil), was microscopically identified as belonging to genus Tilia L. (Malvaceae, ex Tiliaceae), proving its European (not South American) origin.

Key words: "Boy"; Tilia; Vicente Pallotti Museum; Wood Anatomy.

\section{INTRODUÇÃO}

Fundado em 1935 na cidade de Santa Maria, o Museu Vicente Pallotti reúne valioso acervo arqueológico, geológico, paleontológico, bem como de artes visuais, ciências naturais e história, aspecto que o converte em um dos mais importantes do Rio Grande do Sul na atualidade. Um de seus pontos altos é a coleção de imagens sacras do passado missioneiro, a qual, além de numerosa, também se destaca pelo valor histórico e artístico das peças, justificando o recente tombamento de grande parte das mesmas pelo IPHAN - Instituto do Patrimônio Histórico e Artístico Nacional.

1 Recebido em 18-II-2018 e aceito para publicação em 05-IV-2018.

2 Engenheiro Florestal, doutorando do Programa de PósGraduação em Engenharia Florestal, Universidade Federal de Santa Maria, RS, Brasil. barcasole@gmail.com

3 Engenheiro Florestal, Dr. Professor Titular do Departamento de Ciências Florestais, Universidade Federal de Santa Maria.marchioricfl@gmail.com

${ }^{4}$ Historiadora, responsável técnica pelo Museu Vicente Pallotti.museu_pallotti@terra.com.br
A presente linha de pesquisa, que trata da identificação microscópica do lenho das esculturas do referido museu, visa à valorização das mesmas, bem como a elucidar, pelo exame anatômico-estrutural, eventuais pendências no tocante à origem e/ou procedência.

\section{REVISÃO DE LITERATURA}

O exame microscópico permite identificar a espécie botânica de uma amostra de madeira, contribuindo, deste modo, para esclarecer aspectos de interesse para a História da Arte, Museologia, Antropologia e outros campos do conhecimento.

No Rio Grande do Sul, o estudo microscópico de peças arqueológicas e/ou de museus é campo ainda pouco desbravado, salientando-se a obra sobre o uso da madeira nas Reduções Jesuítico-Guarani, publicada pelo IPHAN (Schulze-Hofer \& Marchiori, 2008a), bem como os dez artigos dela extraídos, e que versam sobre a verga da frontaria da Igreja de São Miguel Arcanjo (Schulze-Hofer \& Marchiori, 2008b), a imagem de São José (Marchiori \& SchulzeHofer, 2009), a verga da porta da sacristia nova 
(lado evangelho) da Igreja de São Miguel Arcanjo (Schulze-Hofer \& Marchiori, 2009a), a identidade de um fragmento de madeira obtido por escavação arqueológica na Igreja de São Lourenço (Marchiori \& Schulze-Hofer, 2009b), a imagem de São Lourenço Mártir (Marchiori $\&$ Schulze-Hofer, 2009c), um fragmento remanescente da viga do coro da Igreja de São Miguel Arcanjo (Marchiori \& Schulze-Hofer, 2009d), uma das mísulas do alpendre do Colégio de São Luiz Gonzaga (Schulze-Hofer \& Marchiori, 2009b), um dos pilares do colégio de São Miguel Arcanjo (Marchiori \& Schulze-Hofer, 2010a), a imagem de Santo Estanislau Kostka (Marchiori \& Schulze-Hofer, 2010b) e a imagem de Nossa Senhora das Dores (SchulzeHofer \& Marchiori, 2010).

Mais recentemente, Marchiori \& Machado (2017) investigaram o lenho de três esculturas do Museu Sacro de Santa Maria (Nossa Senhora Missioneira, Santo Antônio de Pádua e Senhor dos Passos), chegando à conclusão de que todas elas foram realizadas em madeira de cedro (Cedrela fissilis Vell., Meliaceae) e que, portanto, são de fatura americana, não européia.

\section{MATERIAL E MÉTODOS}

O material investigado consiste de duas amostras de lenho, extraídas, respectivamente, do corpo e base da escultura. A amostra do corpo foi retirada na lateral da perna esquerda (Figura $1 \mathrm{C}$, seta horizontal), motivo pelo qual, para não causar maiores danos à peça, limitou-se a um simples fragmento (Figura 1D). A outra amostra (Figura 1E) foi extraída na parte posterior da base (Figura 1C, seta vertical).

As amostras foram fervidas em água até a expulsão completa do ar no interior da estrutura lenhosa e, na sequência, seccionadas em micrótomo de deslize (marca Leica), no Laboratório de Anatomia da Madeira da Universidade Federal de Santa Maria (UFSM), obtendo-se cortes anatômicos com espessura nominal de 18 a $24 \mu \mathrm{m}$.

Os cortes anatômicos foram coloridos com safrablau, desidratados em bateria alcoólica
$(25 \%, 50 \%, 75 \%, 90 \%, 95 \%)$ até álcool absoluto, passaram por xilol e foram montados em lâminas permanentes, usando-se "Entellan" como resina.

Como a pesquisa a ser feita visa, tão somente, à identificação anatômica - e não a uma descrição completa -, descartou-se a realização de lâminas de macerado, uma vez que os caracteres anatômicos quantitativos, obtidos a partir das mesmas, não são indispensáveis ao fim proposto.

As fotomicrografias (Figuras 2, 3, 4) foram obtidas em aparelho Leica DM 2000, equipado com câmera digital Leica DCF 295, no Laboratório de Botânica Estrutural do Departamento de Biologia da UFSM.

Na citação de valores quantitativos da estrutura anatômica, o valor que acompanha a média é o desvio padrão e os números entre parênteses correspondem aos valores mínimos e máximos observados.

Para a identificação das amostras de madeira foram consultadas as obras anatômicas citadas em "Referências Bibliográficas".

\section{DESCRIÇÃO MUSEOLÓGICA DA ESCUL- TURA}

Integrante da reserva técnica do Museu Vicente Pallotti, a escultura do "Menino" integra o acervo do referido museu com o número MVP.06.3448. Trata-se de bem ainda não tombado pelo IPHAN (Instituto do Patrimônio Histórico e Artístico Nacional) e de origem desconhecida, procedente de Vale Vêneto (São João do Polêsine, RS) e cedida por doação pelo Padre Clementino Marcuzzo (12-09-1927 - 15-062009) no ano de 1970.

Com $33 \mathrm{~cm}$ de altura, $19 \mathrm{~cm}$ de largura e $21 \mathrm{~cm}$ de profundidade, trata-se de escultura em madeira policromada de figura infantil, com a perna direita ajoelhada, a esquerda flexionada em ângulo de 90 graus, o braço direito sobre o peito, a boca semi-aberta e cabelos encaracolados (Figura 1A, B). Composta de base e corpo, em partes distintas, a peça tem conservação "regular", foi repintada e apresenta desgastes e 

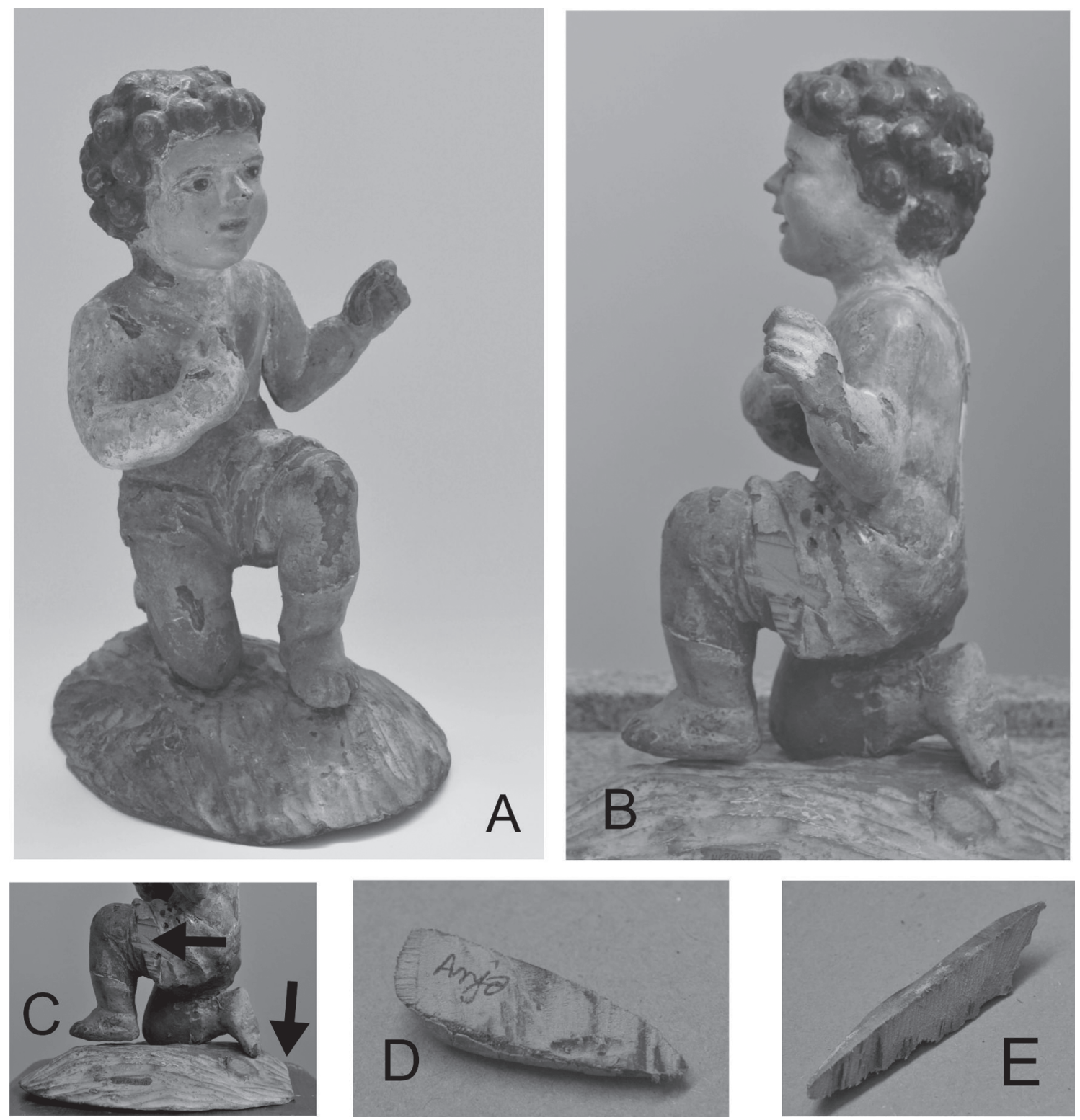

FIGURA 1 - Registro fotográfico da escultura em estudo. A, B - Duas vistas do "Menino". C - Locais de extração das amostras de madeira, indicados por setas. D - Amostra extraída do corpo da escultura (foto muito aumentada em relação à outra). E - Amostra extraída da base da escultura. 
craquelê, bem como sinais do ataque de insetos ao longo do corpo.

\section{DESCRIÇÃO ANATÔMICA}

Os caracteres microscópicos observados no lenho da base (Figuras 2,3) e do corpo (Figura 4) da escultura são resumidos na descrição anatômica a seguir.

Resta comentar que, pelo pequeno tamanho das amostras, não se conseguiram cortes perfeitamente radiais e tangenciais; mesmo assim, as lâminas obtidas permitem o reconhecimento dos caracteres anatômicos necessários. Essa dificuldade não foi sentida com os cortes transversais.

Anéis de crescimento: distintos, marcados por células radialmente estreitas em camada terminal bisseriada (Figura 2B; 3A; 4B), bem como pelos raios mais largos (flaring rays) no limite do anel (Figura 2B; 3A, seta inferior) e pela maior abundância de poros no início do anel seguinte, configurando porosidade semidifusa (Figura 2A).

Vasos: muito abundantes e em porosidade difusa até semidifusa, tendo em vista a ligeira concentração dos mesmos no início de alguns anéis (Figura 2A, B; ). Poros de paredes finas e seção poligonal, estreitos (54 $\pm 9(30-73) \mu \mathrm{m})$, em múltiplos radiais (Figura $2 \mathrm{~A}$ ) e racemiformes de poucas unidades, menos comumente solitários (Figura 3A, seta superior). Elementos vasculares com espessamentos espiralados conspícuos (Figura 2C-E; 3B) e placas de perfuração simples (Figura 3C). Pontoações intervasculares pequenas $(5,2 \pm 0,4(4,6-5,7) \mu \mathrm{m})$, não ornamentadas e em arranjo alterno (Figura $3 \mathrm{D})$. Pontoações raio-vasculares $(3,3 \pm 0,7(2,6$ $-5,2) \mu \mathrm{m})$ e parênquimo-vasculares $(4,6 \pm 0,4$ $(4,1-5,2) \mu \mathrm{m})$, igualmente areoladas e semelhantes às intervasculares, embora menores.

Parênquima axial: apotraqueal difuso-emagregados (Figura 2B, 3A, 4B) e escasso (Figura $3 \mathrm{~A}$, seta superior), composto de séries parenquimáticas com $5 \pm 1,2(3-8)$ células.

Raios: homogêneos e de células procumbentes (Figura 3E; 4C,D), com $3 \pm 1(2-5$ ) células de largura (Figura 2E, F; 4E, F) e $22 \pm$ $10(9$ - 44) células de altura.

Fibras: de paredes relativamente finas ( $\mathrm{Fi}-$ gura 2B, 3A; 4B), com pontoações simples ou pequenas aréolas (Figura 2D, seta; 3F).

\section{DISCUSSÃO}

O exame da estrutura anatômica do lenho da base e corpo da escultura demonstra que ambas as partes foram realizadas com a mesma espécie de madeira.

O único caráter anatômico que permite acesso a uma das chaves de identificação anatômica de Samuel J. Record, publicadas em "Tropical Woods", é a presença de espessamentos espiralados em vasos. Feitas para madeiras do continente americano, as referidas chaves, mesmo assim, também servem - e muito bem - para identificação de espécies holárticas de outras regiões, posto que as floras temperadas da Europa, Ásia e América do Norte reúnem, basicamente, os mesmos gêneros botânicos.

Com base no acima exposto, o manuseio da chave "V - Vessels with Spiral Thickenings" (Record, 1943) leva à identificação do gênero Tília pela seguinte sequência: 1a, fibras sem pontoações areoladas conspícuas: 35 ; 35b, poros, em arranjo não ulmiforme ou tangencial ondulado: 51; 51b, poros, com arranjo não em chama (flame like) ou dendrítico: 68; 68a, parênquima reticulado e, frequentemente, em fina linha terminal: 69; 69b, raios com mais de três células de largura, poros numerosos e pequenos: 70; 70a, estratificação presente, embora não muito distinta, poros muito numerosos e próximos entre si (crowded together), sem arranjo distinto: Tilia.

Descrito por Linnaeus (1753) e por ele incluído na classe Polyandria e ordem Monoginia, o gênero Tilia era tradicionalmente incluído em Tiliaceae, até que estudos morfológicos e moleculares, feitos ao final do século vinte, recomendaram sua agregação a Malvaceae, posição amplamente aceita por autores contemporâneos. 

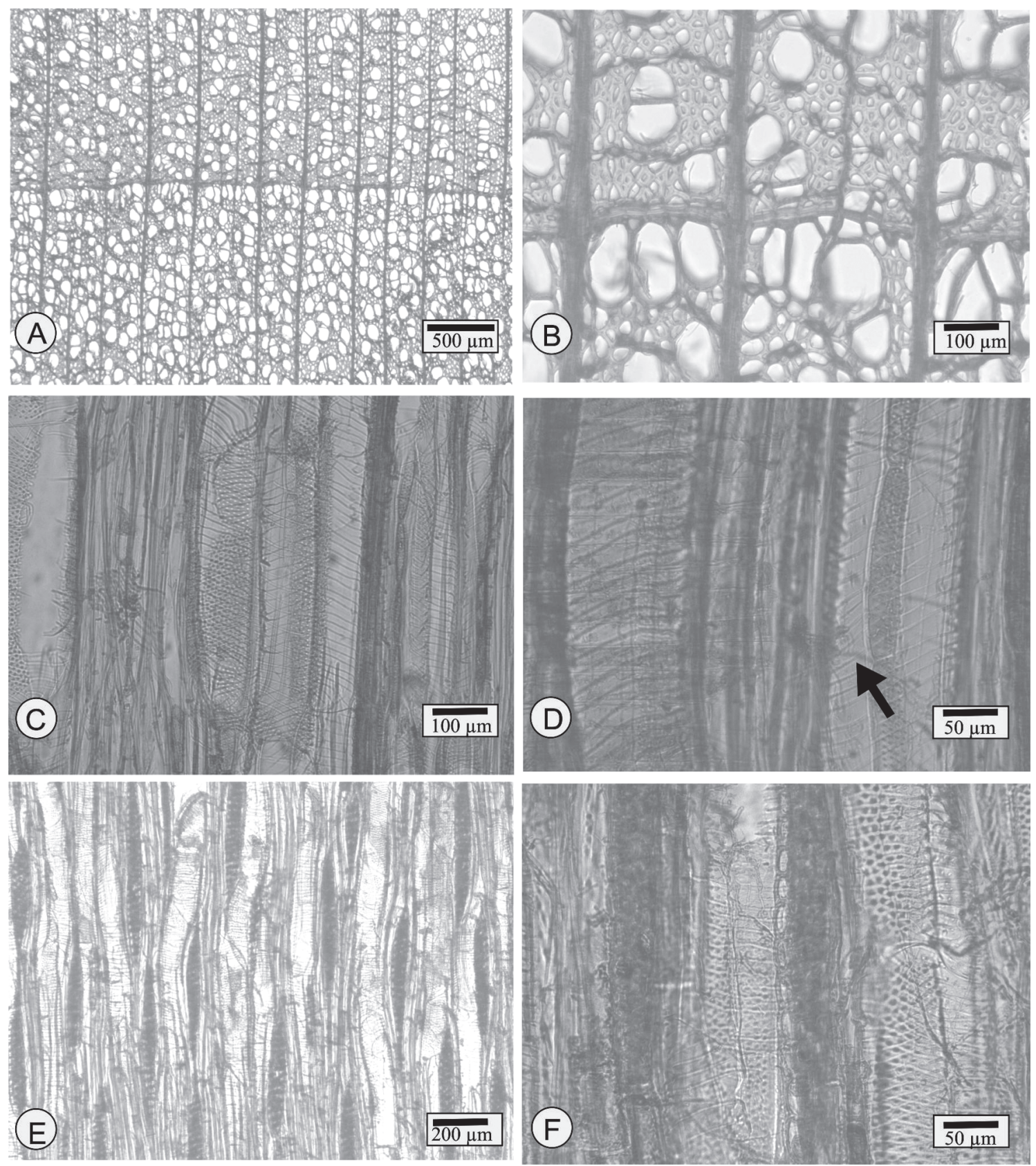

FIGURA 2 - Fotomicrografias do lenho da base da escultura. A - Anéis de crescimento distintos, porosidade difusa a semidifusa e poros extremamente abundantes, poligonais (seção transversal). B - Mesma seção anatômica, salientando poros de seção poligonal e paredes finas, fibras de paredes finas, parênquima apotraqueal difuso-em-agregados e raios mais largos no limite do anel (flaring rays). C, D - Dois aspectos do lenho em seção longitudinal radial, salientando espessamentos espiralados em vasos e pontoações areoladas em fibras (seta). E, F - Dois aspectos do lenho em seção longitudinal tangencial, salientando raios multisseriados e espessamentos espiralados em vasos. 

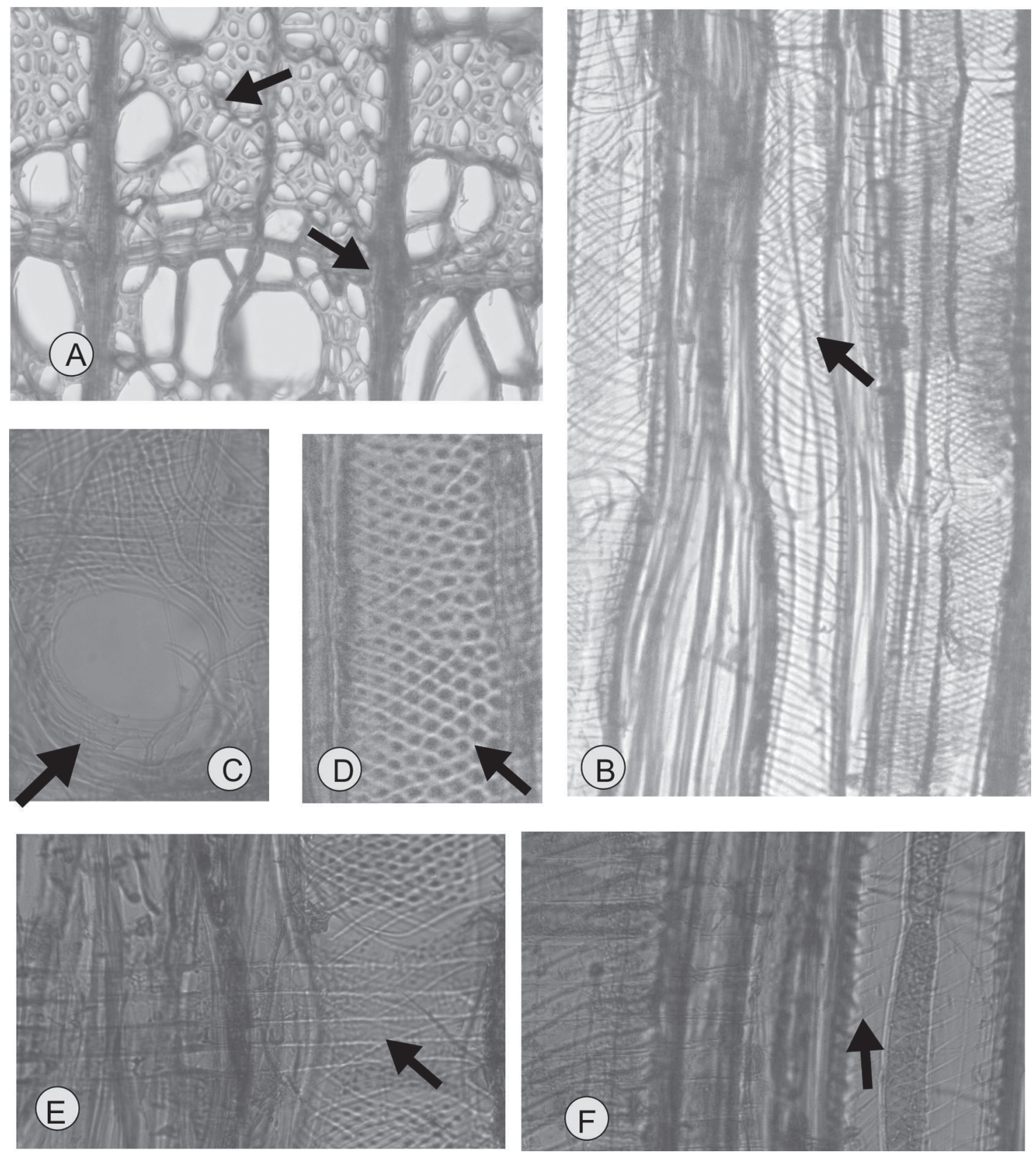

FIGURA 3 - Fotomicrografias de detalhes anatômicos do lenho da base da escultura. A - Seção transversal, destacando uma célula de parênquima apotraqueal difuso (seta superior), bem como o limite de anel, com camada de duas células radialmente estreitas (achatadas) e raio alargado (seta inferior). B - Vasos com espessamentos espiralados (seta). C - Placa de perfuração simples (seta). D - Pontoações intervasculares pequenas e alternas (seta), em seção longitudinal tangencial. E - Raio homogêneo e pontoações raio-vasculares (seta), em seção longitudinal radial. F - Vaso com espessamentos espiralados e fibras de paredes finas, com pontoações areoladas (seta), em seção longitudinal tangencial. 

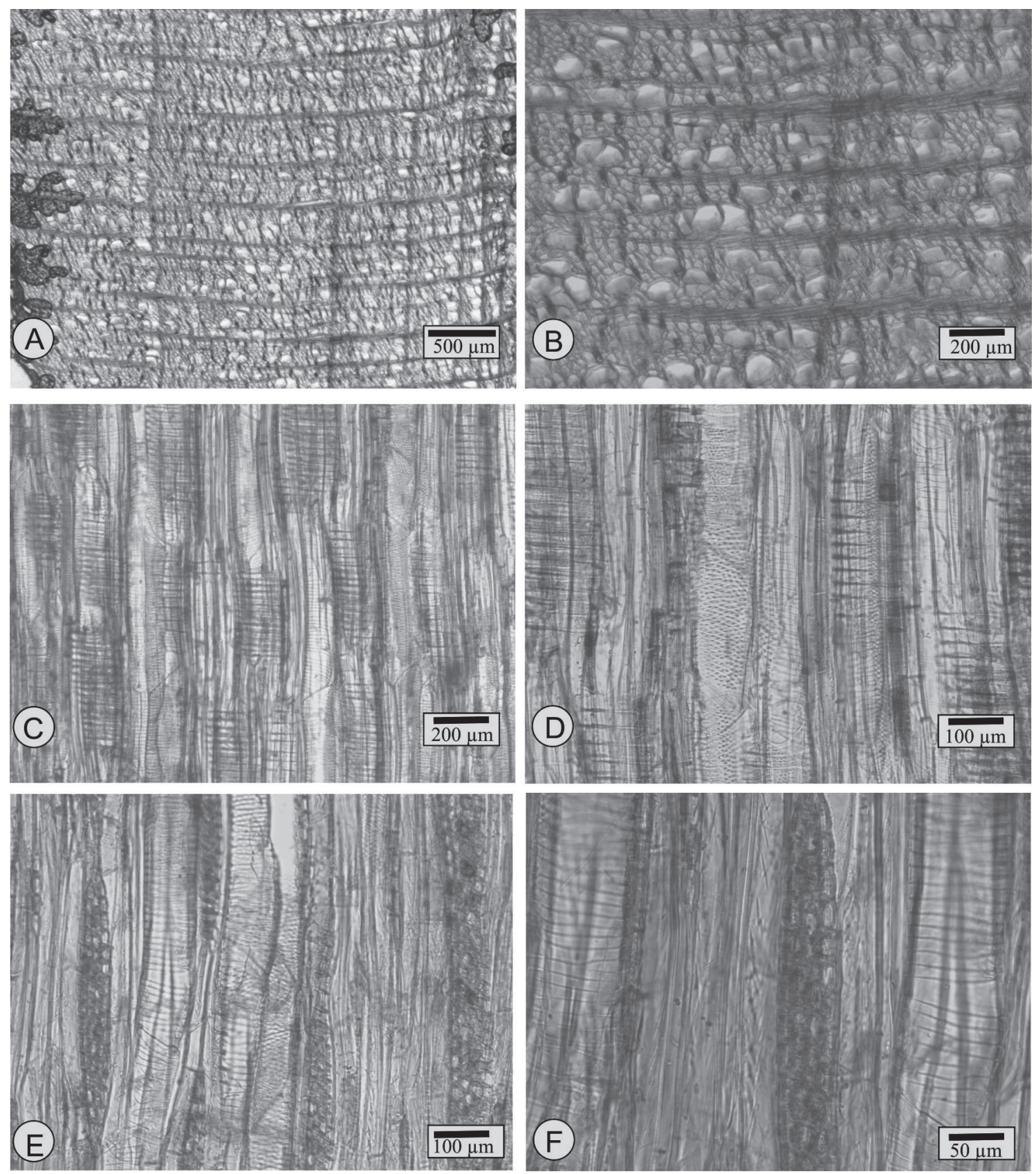

FIGURA 4 - Fotomicrografias do lenho extraído do corpo da escultura. A, B - Anéis de crescimento distintos, porosidade difusa a semidifusa e poros muito numerosos, poligonais e de paredes finas (seção transversal). C, D - Raios homogêneos, de células procumbentes, e pontoações intervasculares pequenas, em arranjo alterno (seção longitudinal radial). E, F - Vasos com espessamentos espiralados e raios com 2-5 células de largura (seção longitudinal tangencial). 
Com cerca de 30 espécies, além de vários híbridos naturais e/ou cultivares, o gênero Tilia distribui-se pelas regiões de clima temperado do Hemisfério Norte (Reino Holártico), com as quatro estações do ano bem demarcadas.

A madeira, dita basswood (em inglês) ou linden (em alemão), é amarelada, relativamente leve e indica-se para diversos usos, inclusive para instrumentos musicais e obras de entalhe.

A identificação de espécies do gênero Tilia torna-se difícil pela semelhança estrutural das distintas espécies. A esse respeito, Schweingruber (1990) assinalou que é difícil, senão impossível, a identificação microscópica dos lenhos de Tilia cordata Mill., Tilia platyphyllos Scop. e Tilia tomentosa Moench, recomendando estudos posteriores, neste sentido, com vistas a elucidar a questão. Para as três espécies, o autor relacionou os seguintes caracteres: cerne indistinto, porosidade difusa a semidifusa, poros em múltiplos radiais e racemiformes (em grupos), limite de anéis de crescimento marcados por 2-3 fileiras de células de paredes espessas, tangencialmente achatadas e com raios distintamente alargados (flaring rays), fibras de paredes relativamente finas, e parênquima apotraqueal, geralmente em curtas linhas unisseriadas, oblíquas ou tangenciais, além de terminal. Este conjunto de caracteres, aliás, concorda, integralmente, com a investigação realizada nos lenhos da base e corpo da escultura, levando à identificação anatômica do gênero Tilia sp.

A estratificação "não muito distinta", apontada por Record (1943), é caráter não citado por Schweingruber (1993) e, igualmente, não reconhecido no material em estudo, a não ser por ligeira tendência no parênquima axial, justificando a ausência de menção sobre o mesmo pelo referido anatomista.

Por ser exótico à flora brasileira, conclui-se que a escultura é de origem estrangeira e, provavelmente, européia.

\section{REFERÊNCIAS BIBLIOGRÁFICAS}

MARCHIORI, J.N.C.; MACHADO, P.F. dos S. Identificação anatômica do lenho de três esculturas do Museu Sacro de Santa Maria. Balduinia, Santa Maria, n. 60, p. 11-28, 2017.

MARCHIORI, J.N.C.; SCHULZE-HOFER, M.C. O uso da madeira nas Reduções Jesuítico-Guarani do Rio Grande do Sul. 3 - Imagem de São José. Balduinia, Santa Maria, n. 15, p. 1-4, 2009a.

MARCHIORI, J.N.C.; SCHULZE-HOFER, M.C. O uso da madeira nas Reduções Jesuítico-Guarani do Rio Grande do Sul. 5 - Fragmento de madeira procedente de escavações arqueológicas no átrio da Igreja de São Lourenço. Balduinia, Santa Maria, n. 16, p. 1-5, 2009 b.

MARCHIORI, J.N.C.; SCHULZE-HOFER, M.C. O uso da madeira nas Reduções Jesuítico-Guarani do Rio Grande do Sul. 6 - Imagem de São Lourenço Mártir. Balduinia, Santa Maria, n. 17, p. 7-10, 2009c.

MARCHIORI, J.N.C.; SCHULZE-HOFER, M.C. O uso da madeira nas Reduções Jesuítico-Guarani do Rio Grande do Sul. 7 - Viga do coro da Igreja de São Miguel Arcanjo. Balduinia, Santa Maria, n. 17, p. 29-33, 2009d.

MARCHIORI, J.N.C.; SCHULZE-HOFER, M.C. O uso da madeira nas Reduções Jesuítico-Guarani do Rio Grande do Sul. 9 - Pilar do Colégio de São Miguel Arcanjo. Balduinia, Santa Maria, n. 20, p. 5-9, 2010a.

MARCHIORI, J.N.C.; SCHULZE-HOFER, M.C. O uso da madeira nas Reduções JesuíticoGuarani do Rio Grande do Sul. 10 - Imagem de Santo Estanislau Kostka. Balduinia, Santa Maria, n. 21, p. 29-32, 2010 b.

RECORD, S.J. Keys to American Woods (continued). Tropical Woods, New Haven, n. 73, p. 33-42, 1943.

SCHULZE-HOFER, M.C.; MARCHIORI, J.N.C. $O$ uso da madeira nas Reduções Jesuítico-Guarani do Rio Grande do Sul. Porto Alegre: IPHAN, 2008a. 80 p.

SCHULZE-HOFER, M.C.; MARCHIORI, J.N.C. O uso da madeira nas Reduções Jesuítico-Guarani do Rio Grande do Sul. 2 - Verga da frontaria da Igreja de São Miguel Arcanjo. Balduinia, Santa Maria, n. 14, p. 29-32, 2008b. 
SCHULZE-HOFER, M.C.; MARCHIORI, J.N.C. O uso da madeira nas Reduções Jesuítico-Guarani do Rio Grande do Sul. 4 - Verga da porta da Sacristia Nova (lado evangelho) da Igreja de São Miguel Arcanjo. Balduinia, Santa Maria, n. 15, p. 24-27, 2009a.

SCHULZE-HOFER, M.C.; MARCHIORI, J.N.C. O uso da madeira nas Reduções Jesuítico-Guarani do Rio Grande do Sul. 8 - Mísula do alpendre do Colégio de São Luiz Gonzaga. Balduinia,
Santa Maria, n. 19, p. 14-18, 2009 b.

SCHULZE-HOFER, M.C.; MARCHIORI, J.N.C. O uso da madeira nas Reduções Jesuítico-Guarani do Rio Grande do Sul. 11 - Imagem de Nossa Senhora das Dores. Baölzerlduinia, Santa Maria, n. 22, p. 31-34, 2010.

SCHWEINGRUBER, F.H. Anatomie europäischer Hölzer, ein Atlas zur Bestimmung europäischer Baum, Strauch- und Zwergstrauchhölzer. Bern: Haupt, 1990. 800p. 